\title{
Research on Enterprise Marketing Capability Measure Method based on Fuzzy Multi-attribute Analysis Model
}

\author{
Fei Lu \\ Chongqing academy of social and science, Chongqing, China \\ skylufei@126.com
}

\begin{abstract}
Influenced by many factors, enterprise marketing capability is essential for improving the enterprise marketing competitiveness and its sustainable development. By studying the factors comprehensively and effectively, the enterprise can better recognize their marketing capability and the direction of improvement. This paper studies and analyzes the enterprise marketing capability measure methods and proposes a new one based on fuzzy multi-attribute analysis model. This model recognizes the marketing capability of marketing plans from different enterprises by providing the evaluation indicators of marketing capability measure, establishing related evaluation index system, conducting the membership analysis of different kinds of capability measure indicators, and calculating Euclidean distance and fuzzy subordinate degree of those indicators. Finally, the practicality and feasibility of the model and algorithm is proved by case analysis and verification of marketing plans from different enterprises.
\end{abstract}

Keywords: Marketing capability; fuzzy mathematics; multi-attribute evaluation; measure method; model

\section{Introduction}

With the rapid development of science and technology and the dramatic change of market circumstances, the development ability and marketing competitiveness of enterprises are increasingly determined by various factors. Many relevant researches have discussed how to improve the development ability and marketing competitiveness of enterprises, making it a hot issue in enterprise marketing studies [1-3]. With the complexity and variability of different influential factors, especially the constant development and change of the enterprise marketing condition against the background of current development of science and technology, enterprise marketing capability has become essential to an enterprise's development ability and competitiveness. More and more scholars have been studying and discussing this issue, proposing measures according to different marketing condition, and completing the theoretical studies and engineering practices [4-8]. This paper believes that two things should be done to analyze marketing capability and propose measures for improvement. Firstly, a scientific measure index system of enterprise marketing capability should be constructed. Secondly, the effective and feasible model and algorithm for measuring marketing capability should be established. This is extremely important and practically valuable for improving the enterprise's development ability, marketing capability and competitiveness. After understanding the information of the complication and fuzzy measure in the process of the capacity analysis, this paper proposes solutions to the improvement of previous research methods. Based on the former researches, it creates an enterprise marketing capability measure method based on fuzzy multi-attribute analysis 
model from the perspective of fuzzy math [9-13], providing a new solution for improving enterprise capability.

\section{Index Analysis System of Enterprise Marketing Capability}

Different aspects of the enterprise marketing should be considered when choosing the measure analysis index of enterprise marketing capability. The construction principles should be scientific, object, comprehensive and systematic, considering not only the product content and internal factors of the enterprise marketing, but also market extension and external factors so that the enterprise marketing capability can be distinguished from the enterprise competitiveness. Guided by the principles mentioned above and based on the existing researches, this paper divides the enterprise marketing capability into four components: product competitiveness, value capability, development ability, and service ability. Product competitiveness is the links of product development related to product design and manufacture. It directly reflects the capability of the products to meet customers' needs, and can be measured according to product development quality and period. Value capability means the ability to achieve the established marketing goals, which can be measured by price planning and regulating capability. Development ability refers to the market penetrating ability of the product to sustain its development, measured by the brand power and the synergy capability. Service ability signifies the ability to provide after-sale service, measured by the service feedback and maintenance and repair ability. Thus the composition of the index analysis system of enterprise marketing capability is shown in Table 1.

Table 1. Index Analysis System of Enterprise Marketing Capability

\begin{tabular}{|c|c|c|}
\hline $\begin{array}{c}\text { System } \\
\text { layer }\end{array}$ & $\begin{array}{c}\text { Criterion } \\
\text { layer }\end{array}$ & Indicator layer \\
\hline \multirow{8}{*}{$\begin{array}{c}\text { index } \\
\text { analysis } \\
\text { system of } \\
\text { enterprise } \\
\text { marketing } \\
\text { capability } \\
\Omega\end{array}$} & \multirow{2}{*}{$\begin{array}{l}\text { product } \\
\text { competitive } \\
\text { ness } P_{1}\end{array}$} & $\begin{array}{c}\text { Product } \\
\text { development } \\
\text { quality } p_{11}\end{array}$ \\
\hline & & $\begin{array}{c}\text { Product } \\
\text { development } \\
\text { period } p_{12}\end{array}$ \\
\hline & \multirow{2}{*}{$\begin{array}{c}\text { Value } \\
\text { capability } \\
P_{2}\end{array}$} & $\begin{array}{l}\text { Price planning } \\
\text { ability } p_{21}\end{array}$ \\
\hline & & $\begin{array}{c}\text { Price regulation } \\
\text { ability } p_{22} \\
\end{array}$ \\
\hline & \multirow{2}{*}{$\begin{array}{l}\text { developme } \\
\text { nt ability } P_{3}\end{array}$} & brand power $p_{31}$ \\
\hline & & $\begin{array}{c}\text { synergy } \\
\text { capability } p_{32}\end{array}$ \\
\hline & \multirow{2}{*}{$\begin{array}{c}\text { service } \\
\text { ability } P_{4}\end{array}$} & $\begin{array}{c}\text { service feedback } \\
\text { ability } p_{41}\end{array}$ \\
\hline & & $\begin{array}{l}\text { maintenance and } \\
\text { repair capability } p_{42}\end{array}$ \\
\hline
\end{tabular}




\section{Evaluation of Enterprise Marketing Capability based on Multi-attribute Fuzzy Analysis Model}

\subsection{Program Set of Enterprise Marketing Capability Measure and Index Value Matrix}

Suppose there are $\mathrm{n}$ analysis programs of enterprise marketing capability measure forming a program set $C=\left(C_{1}, C_{2}, \cdots, C_{n}\right)$. According to the index analysis system of enterprise marketing capability, the corresponding index set of measure analysis in the criterion layer is $P=\left(P_{1}, P_{2}, P_{3}, P_{4}\right)$, with $P_{1}=\left(p_{11}, p_{12}\right), P_{2}=\left(p_{21}, p_{22}\right), P_{3}=\left(p_{31}, p_{32}\right), P_{4}=\left(p_{41}, p_{42}\right)$. Then the index values in the criterion layer of the $\mathrm{n}$ programs result in corresponding index analysis matrix of the enterprise marketing capability. That is:

$$
A_{n \times 8}=\left[\begin{array}{cccccccc}
a_{11}^{1} & a_{12}^{1} & a_{21}^{1} & a_{22}^{1} & a_{31}^{1} & a_{32}^{1} & a_{41}^{1} & a_{42}^{1} \\
\vdots & \vdots & \vdots & \vdots & \vdots & \vdots & \vdots & \vdots \\
a_{11}^{n} & a_{12}^{n} & a_{21}^{n} & a_{22}^{n} & a_{31}^{n} & a_{32}^{n} & a_{41}^{n} & a_{42}^{n}
\end{array}\right]_{n \times 8}
$$

In this matrix, $a_{i j}^{k}$ represents the value of measure analysis index $j$ of criterion layer $i$ in program $k$. If it is fixed index, then it represents the index value. If it is fuzzy index, then the value can be worked out using its membership function.

\subsection{The Membership Function of the Analysis Index of Enterprise Capability Measure}

The analysis index of enterprise capability measure probably consists of three kinds: benefit-oriented index that features bigger is better; cost-oriented index featuring smaller is better; moderation index that prefers the middle optimal value. This paper provides the membership function formulas of the three kinds accordingly. They are as follows.

Formula for benefit-oriented index:

$$
v_{i j}^{k}= \begin{cases}1 & a_{i j}^{k} \geq \max _{1 \leq k \leq n} a_{i j}^{k} \\ \frac{a_{i j}^{k}-\min _{1 \leq k \leq n} a_{i j}^{k}}{\max _{1 \leq k \leq n} a_{i j}^{k}-\min _{1 \leq k \leq n} a_{i j}^{k}} & \min _{1 \leq k \leq n} a_{i j}^{k} \leq a_{i j}^{k} \leq \max _{1 \leq k \leq n} a_{i j}^{k} \\ 0 & a_{i j}^{k} \leq \min _{1 \leq k \leq n} a_{i j}^{k}\end{cases}
$$

Formula for cost-oriented index:

$$
v_{i j}^{k}= \begin{cases}1 & a_{i j}^{k} \leq \min _{1 \leq k \leq n} a_{i j}^{k} \\ \frac{\max _{1 \leq k \leq n} a_{i j}^{k}-a_{i j}^{k}}{\max _{1 \leq k \leq n} a_{i j}^{k}-\min _{1 \leq k \leq n} a_{i j}^{k}} & \min _{1 \leq k \leq n} a_{i j}^{k} \leq a_{i j}^{k} \leq \max _{1 \leq k \leq n} a_{i j}^{k} \\ 0 & a_{i j}^{k} \geq \max _{1 \leq k \leq n} a_{i j}^{k}\end{cases}
$$

Formula for moderation index: 


$$
v_{i j}^{k}= \begin{cases}1 & a_{i j}^{k}=\frac{\max _{1 \leq k \leq n} a_{i j}^{k}+\min _{1 \leq k \leq n} a_{i j}^{k}}{2} \\ \frac{a_{i j}^{k}-\min _{1 \leq k \leq n} a_{i j}^{k}}{\max _{1 \leq k \leq n}^{k}+\min _{1 \leq k \leq n} a_{i j}^{k}}-\min _{1 \leq k \leq n} a_{i j}^{k} & \min _{1 \leq k \leq n} a_{i j}^{k} \leq a_{i j}^{k}<\frac{\max _{1 \leq k \leq n} a_{i j}^{k}+\min _{1 \leq k \leq n} a_{i j}^{k}}{2} \\ \frac{\max _{1 \leq k \leq n} a_{i j}^{k}-a_{i j}^{k}}{2} & \frac{\max _{1 \leq k \leq n} a_{i j}^{k}+\min _{1 \leq k \leq n} a_{i j}^{k}}{2}<a_{i j}^{k} \leq \max _{1 \leq k \leq n} a_{i j}^{k} \\ \frac{\max _{1 \leq k \leq n} a_{i j}^{k}+\min _{1 \leq k \leq n} a_{i j}^{k}}{2}-\min _{1 \leq k \leq n} a_{i j}^{k} & \left(a_{i j}^{k} \geq \max _{1 \leq k \leq n} a_{i j}^{k}\right) \vee\left(a_{i j}^{k} \leq \min _{1 \leq k \leq n} a_{i j}^{k}\right)\end{cases}
$$

By studying the corresponding membership function formulas of the analysis index of enterprise marketing measure, we can get the corresponding function matrix $V_{n \times 8}$ :

$$
V_{n \times 8}=\left[\begin{array}{cccccccc}
v_{11}^{1} & v_{12}^{1} & v_{21}^{1} & v_{22}^{1} & v_{31}^{1} & v_{32}^{1} & v_{41}^{1} & v_{42}^{1} \\
\vdots & \vdots & \vdots & \vdots & \vdots & \vdots & \vdots & \vdots \\
v_{11}^{n} & v_{12}^{n} & v_{21}^{n} & v_{22}^{n} & v_{31}^{n} & v_{32}^{n} & v_{41}^{n} & v_{42}^{n}
\end{array}\right]_{n \times 8}
$$

\subsection{Measure Analysis Index Fuzzy Distance of Marketing Capability}

The combination of positive fuzzy distance and negative fuzzy distance is required in order to obtain effective measure analysis index fuzzy distance of marketing capability. According to the membership function matrix of enterprise marketing capability measure analysis index, the positive optimal fuzzy membership vector $H_{\max }$ and the negative worst fuzzy membership vector $H_{\min }$ of different measure analysis indexes are determined as followings:

$$
\begin{aligned}
& H_{\max }= \\
& \left(\max _{1 \leq k \leq n} v_{11}^{k}, \max _{1 \leq k \leq n} v_{12}^{k}, \max _{1 \leq k \leq n} v_{21}^{k}, \max _{1 \leq k \leq n} v_{22}^{k}, \max _{1 \leq k \leq n} v_{31}^{k}, \max _{1 \leq k \leq n} v_{32}^{k}, \max _{1 \leq k \leq n} v_{41}^{k}, \max _{1 \leq k \leq n} v_{42}^{k}\right) \\
& H_{\min }= \\
& \left(\min _{1 \leq k \leq n} v_{11}^{k}, \min _{1 \leq k \leq n} v_{12}^{k}, \min _{1 \leq k \leq n} v_{21}^{k}, \min _{1 \leq k \leq n} v_{22}^{k}, \min _{1 \leq k \leq n} v_{31}^{k}, \min _{1 \leq k \leq n} v_{32}^{k}, \min _{1 \leq k \leq n} v_{41}^{k}, \min _{1 \leq k \leq n} v_{42}^{k}\right)
\end{aligned}
$$

If the relative weights of the evaluation indexes are known as $W=\left(w_{11}, w_{12}, w_{21}, w_{22}, w_{31}, w_{32}, w_{41}, w_{42}\right)$, then the optimal fuzzy distance $D_{i j}^{k}(\max )$ of the measure analysis program of enterprise marketing capability $C_{k}$ about measure analysis evaluation index $p_{i j}$ is:

$$
D_{i j}^{k}(\max )=\sqrt{\sum_{j=1}^{r_{i}}\left(w_{i j} *\left(\max _{1 \leq k \leq n} v_{i j}^{k}-v_{i j}^{k}\right)^{2}\right)}
$$

Likewise, the worst fuzzy distance $D_{i j}^{k}(\mathrm{~min})$ of the measure analysis program of enterprise marketing capability $C_{k}$ about measure analysis evaluation index $p_{i j}$ is 


$$
D_{i j}^{k}(\min )=\sqrt{\sum_{j=1}^{r_{i}}\left(w_{i j} *\left(v_{i j}^{k}-\min _{1 \leq k \leq n} v_{i j}^{k}\right)^{2}\right)}
$$

$r_{i}$ represents the number of measure analysis evaluation indexes $p_{i j}$ under the criteria of measure analysis $P_{i}$.

In order to ensure a more complete measure analysis of enterprise marketing capability, both the optimal fuzzy distance and worst fuzzy distance of measure analysis program $C_{k}$ about measure analysis evaluation index $p_{i j}$ should be considered synthetically. Therefore, if the fuzzy membership degree of the positive optimal fuzzy membership vector $H_{\max }$ of the enterprise marketing capability measure analysis program $C_{k}$ about measure analysis evaluation index $p_{i j}$ is $\varphi_{i j}^{k}(\max )$, and the fuzzy membership degree of the negative worst fuzzy membership vector $H_{\min }$ of program $C_{k}$ about measure analysis evaluation index $p_{i j}$ is $\varphi_{i j}^{k}(\min )$, then the optimal fuzzy membership degree distance $d_{i j}^{k} \mid \varphi_{i j}^{k}(\max )$ and the worst fuzzy membership degree distance $d_{i j}^{k} \mid \varphi_{i j}^{k}(\mathrm{~min})$ of the enterprise marketing capability measure analysis program $C_{k}$ about measure analysis evaluation index $p_{i j}$ are:

$$
\begin{aligned}
& d_{i j}^{k} \mid \varphi_{i j}^{k}(\max )=\varphi_{i j}^{k}(\max ) * D_{i j}^{k}(\max ) \\
& d_{i j}^{k} \mid \varphi_{i j}^{k}(\min )=\varphi_{i j}^{k}(\min ) * D_{i j}^{k}(\min ) \\
& \varphi_{i j}^{k}(\max )+\varphi_{i j}^{k}(\min )=1
\end{aligned}
$$

The objective function $F\left(d_{i j}^{k} \mid \varphi_{i j}^{k}(\max )\right)$ of the optimal fuzzy membership degree distance based on the advantages and disadvantages of the enterprise marketing capability measure analysis program $C_{k}$ about measure analysis evaluation index $p_{i j}$ is:

$$
\left\{\begin{array}{l}
F\left(d_{i j}^{k} \mid \varphi_{i j}^{k}(\max )\right)=\min \quad\left\{\left[\varphi_{i j}^{k}(\max ) * D_{i j}^{k}(\max )\right]^{2}+\left[\varphi_{i j}^{k}(\min ) * D_{i j}^{k}(\min )\right]^{2}\right\} \\
0 \leq \varphi_{i j}^{k}(\max ) \leq 1 \\
0 \leq \varphi_{i j}^{k}(\min ) \leq 1
\end{array}\right.
$$

Thus, the fuzzy membership degree $\varphi_{i j}^{k}(\max )$ of the positive optimal fuzzy membership vector $H_{\max }$ of the enterprise marketing capability measure analysis program $C_{k}$ about measure analysis evaluation index $p_{i j}$ is:

$$
\varphi_{i j}^{k}(\max )=\frac{1}{1+\left(D_{i j}^{k}(\max ) / D_{i j}^{k}(\min )\right)^{2}}
$$

\subsection{Model and Algorithm Implementation based on Fuzzy Membership Degree}

According to Formula (14), the fuzzy membership degree of the enterprise marketing capability measure analysis program $C_{k}$ about measure analysis evaluation index $p_{i j}$ is 
$\varphi_{i j}^{k}(\max )$, so the fuzzy membership degree $\varphi_{i}^{k}(\max )$ of the enterprise marketing capability measure analysis program $C_{k}$ about measure analysis evaluation criterion $P_{i}$ is:

$$
\varphi_{i}^{k}(\max )=\sum_{j=1}^{r_{i}}\left(w_{i j} * \varphi_{i j}^{k}(\max )\right)
$$

If the weight of different measure analysis evaluation criterion $P_{i}$ is $W_{i}$, then the weighted fuzzy membership degree $\varphi_{S}^{k}(\max )$ of the enterprise marketing capability measure analysis program $C_{k}$ about measure analysis evaluation criterion $P_{i}$ is:

$$
\varphi_{S}^{k}(\max )=\sum_{i=1}^{n}\left(W_{i} * \varphi_{i}^{k}(\max )\right)
$$

The quality of different measure analysis schemes of enterprise marketing capability can be seen based on the value of the weighted fuzzy membership degree $\varphi_{S}^{k}(\max )$. The optimization principle is shown in Formula (17):

$$
\varphi_{0}^{k}(\max )=\max \left(\varphi_{1}^{k}(\max ), \varphi_{2}^{k}(\max ), \cdots, \varphi_{m}^{k}(\max )\right)=\varphi_{t}^{k}(\max )
$$

\section{Case Analysis and Verification}

This paper conducts the marketing capability measure analysis on three listed companies of a certain industry through the proposed enterprise marketing capability measure method based on fuzzy multi-attribute analysis model to show its practicability and feasibility. The measure analysis evaluation index value based on the measure analysis index system of enterprise marketing capability is obtained through market research of the three companies and the statistical analysis of relevant marketing data. Meanwhile, the weight of each evaluation indicator is decided according to experts' grading. The specific data are shown in Table 2.

\begin{tabular}{|c|c|c|c|c|c|c|c|}
\hline Criterion layer & Weight & Indicator layer & $\begin{array}{ll}\begin{array}{l}\text { Type } \\
\text { indicator }\end{array} & \text { of } \\
\end{array}$ & Weight & $\begin{array}{l}\begin{array}{l}\text { Enterprise } \\
\text { scheme A }\end{array} \\
\end{array}$ & $\begin{array}{l}\begin{array}{l}\text { Enterprise } \\
\text { scheme B }\end{array} \\
\end{array}$ & $\begin{array}{l}\text { Enterprise } \\
\text { scheme C }\end{array}$ \\
\hline \multirow{2}{*}{$\begin{array}{l}\text { Product } \\
\text { competitiveness } \\
P_{1}\end{array}$} & \multirow{2}{*}{0.26} & $\begin{array}{l}\text { Product development } \\
\text { quality } p_{11}\end{array}$ & $\begin{array}{l}\text { benefit- } \\
\text { oriented index }\end{array}$ & 0.55 & 92 & 85 & 90 \\
\hline & & $\begin{array}{l}\text { Product development } \\
\text { period } p_{12}\end{array}$ & $\begin{array}{l}\text { cost-oriented } \\
\text { index }\end{array}$ & 0.45 & 4.6 & 4.2 & 5.5 \\
\hline \multirow{2}{*}{$\begin{array}{l}\text { Value capability } \\
P_{2}\end{array}$} & \multirow{2}{*}{0.34} & $\begin{array}{ll}\text { Price } & \text { planning } \\
\text { ability } p_{21} & \end{array}$ & $\begin{array}{l}\text { benefit- } \\
\text { oriented index }\end{array}$ & 0.60 & 0.85 & 0.90 & 0.80 \\
\hline & & $\begin{array}{l}\text { Price regulation } \\
\text { ability } p_{22}\end{array}$ & $\begin{array}{l}\text { benefit- } \\
\text { oriented index }\end{array}$ & 0.40 & 0.75 & 0.80 & 0.80 \\
\hline \multirow{2}{*}{$\begin{array}{l}\text { Development } \\
\text { ability } \\
P_{3}\end{array}$} & \multirow[b]{2}{*}{0.22} & Brand power $p_{31}$ & $\begin{array}{l}\text { benefit- } \\
\text { oriented index }\end{array}$ & 0.60 & 95 & 85 & 90 \\
\hline & & $\begin{array}{l}\text { Synergy capability } \\
p_{32}\end{array}$ & $\begin{array}{l}\text { benefit- } \\
\text { oriented index }\end{array}$ & 0.40 & 10 & 6 & 9 \\
\hline $\begin{array}{l}\text { Service ability } \\
P_{4}\end{array}$ & 0.18 & $\begin{array}{ll}\text { Service } & \text { feedback } \\
\text { ability } p_{41} & \end{array}$ & $\begin{array}{l}\text { cost-oriented } \\
\text { index }\end{array}$ & 0.50 & 24 & 48 & 24 \\
\hline
\end{tabular}

\section{Table 2. Value of Enterprise Marketing Capability Measure Evaluation Analysis Index}




\begin{tabular}{|l|l|l|l|l|l|l|l|}
\hline & $\begin{array}{l}\text { Maintenance and } \\
\text { repair capability } \\
p_{42}\end{array}$ & $\begin{array}{l}\text { benefit- } \\
\text { oriented index }\end{array}$ & 0.50 & 0.90 & 0.90 & 0.85 \\
\hline
\end{tabular}

Enterprise marketing capability measure analysis index matrix is drawn as $\boldsymbol{A}_{3 \times 8}$ :

$$
\boldsymbol{A}_{3 \times 8}=\left[\begin{array}{cccccccc}
92 & 4.6 & 0.85 & 0.75 & 95 & 10 & 24 & 0.90 \\
85 & 4.2 & 0.90 & 0.80 & 85 & 6 & 48 & 0.90 \\
90 & 5.5 & 0.80 & 0.80 & 90 & 9 & 24 & 0.85
\end{array}\right]_{3 \times 8} \text {. }
$$

Based on the processing method of measure analysis index membership function of marketing capability discussed in 2.2 , the enterprise marketing capability measure analysis index membership matrix $\boldsymbol{V}_{3 \times 8}$ can be drawn:

$$
\boldsymbol{V}_{3 \times 8}=\left[\begin{array}{cccccccc}
1.000 & 0.692 & 0.500 & 0 & 1.000 & 1.000 & 1.000 & 1.000 \\
0 & 1.000 & 1.000 & 1.000 & 0 & 0 & 0 & 1.000 \\
0.714 & 0 & 0 & 1.000 & 0.500 & 0.750 & 1.000 & 0
\end{array}\right]_{3 \times 8}
$$

Then the optimal fuzzy distance matrix $\boldsymbol{D}(\max )$ and the worst fuzzy distance matrix $\boldsymbol{D}(\mathrm{min})$ of enterprise marketing capability measure analysis program about measure analysis evaluation index can be obtained.

$$
\begin{aligned}
\boldsymbol{D}(\text { max })_{3 \times 8} & =\left[\begin{array}{cccccccc}
0 & 0.207 & 0.387 & 0.632 & 0 & 0 & 0 & 0 \\
0.741 & 0 & 0 & 0 & 0.775 & 0.642 & 0.707 & 0 \\
0.212 & 0.671 & 0.775 & 0 & 0.387 & 0.158 & 0 & 0.707
\end{array}\right]_{3 \times 8} \\
\boldsymbol{D}(\min )_{3 \times 8} & =\left[\begin{array}{cccccccc}
0.741 & 0.464 & 0.387 & 0 & 0.775 & 0.632 & 0.707 & 0.707 \\
0 & 0.671 & 0.775 & 0.632 & 0 & 0 & 0 & 0.707 \\
0.550 & 0 & 0 & 0.632 & 0.387 & 0.474 & 0.707 & 0
\end{array}\right]_{3 \times 8}
\end{aligned}
$$

Then the fuzzy distance of enterprise marketing capability measure analysis program about criterion layer measure analysis evaluation index can be obtained, as is shown in Table 3.

Table 3. Fuzzy Distance of Criterion Layer in Enterprise Marketing Capability Measure Evaluation Analysis

\begin{tabular}{|l|l|l|l|}
\hline & $\begin{array}{l}\text { Enterprise } \\
\text { scheme A }\end{array}$ & $\begin{array}{l}\text { Enterprise } \\
\text { scheme B }\end{array}$ & $\begin{array}{l}\text { Enterprise } \\
\text { scheme C }\end{array}$ \\
\hline $\begin{array}{l}\text { Optimal fuzzy } \\
\text { distance }\end{array}$ & 0.200 & 0.316 & 0.370 \\
\hline $\begin{array}{l}\text { Worst fuzzy } \\
\text { distance }\end{array}$ & 0.505 & 0.390 & 0.337 \\
\hline
\end{tabular}

Based on the computational formula of fuzzy membership degree, the fuzzy membership degree sequence of the marketing capability measure analysis program of the three companies is gained, namely $\varphi=(0.864,0.603,0.453)$. According to the optimization principle of the program, enterprise A has better marketing capability, which is consistent with the real situation. Meanwhile, it can be seen based on the measure analysis results that although enterprise A has better marketing capability, it has weakness in specific implementation of marketing. For example, it is relatively poor at price planning and regulation. Therefore it 
should improve the two aspects in the future marketing in order to effectively improve its marketing capability. Similarly, enterprise B and C can also refer to the relevant measure analysis results and take steps to improve their marketing capability.

\section{Conclusion}

This paper analyzes the relevant factors that influence enterprise marketing capability and proposes the evaluation index system for enterprise marketing capability measure analysis. Through the membership function calculation of different types of measure analysis indicators, the optimal fuzzy distance and the worst fuzzy distance of enterprise marketing capability measure analysis index are constructed. The fuzzy membership degree of enterprise marketing capability measure analysis is obtained with completeness, according to which an enterprise marketing capability measure method based on multi-attribute fuzzy analysis model is formed. Thus, the enterprise marketing capability measure analysis under multiattribute influence is realized, providing a new solution to the improvement of enterprise marketing competence and sustainable development capacity. This paper verifies and explains the model and its algorithms through specific case study. The verification of the example is consistent with the real situation of enterprise marketing, showing the validity of the model and its algorithms proposed by the paper.

\section{Acknowledgements}

This paper belongs to the project of "the research of Enterprise salary collective consultation”, supported by Chongqing Social Science Foundation (No. 2012YBSH050)

\section{References}

[1] Y. Rashad, M. Tshepo and M. M. Uarba, "Project management and project integration management in relationship with service marketing [C]", International Conference on Management and Service Science, Wuhan, China: IEEE Computer Society Press, (2011), pp. 1-4.

[2] Z. Song and L. Zhao, "Construction and Analysis of Marketing Capability Evaluation Model [J]", Commercial Times, vol. 24, (2011), pp. 31 -32.

[3] J. Xu and Y.-1. Ren, "Application of Extension Method in Choosing Target Market of Electricity Marketing [J]”, Journal of Chongqing University, vol. 26, no. 11, (2003), pp. 142-145+154.

[4] J. Xu and Y.-long Ren, "Application of Extension Method in Choosing Target Market of Electricity Marketing [J]", Journal of Chongqing University, vol. 26, no. 11, (2003), pp. 142-145+154.

[5] Q. Zhang and S. Liu, "Marketing Capability Evaluation Model of Tourism Enterprise based on AHP [J]", Enterprise Economy, vol. 1, (2010), pp. 101-103.

[6] Z. Hu, Y. Wang and J. Yang, "Evaluation of Enterprise Marketing Capability based on Fuzzy Comprehensive Evaluation Method [J]", Statistics and Decision, vol. 2, (2011), pp. 173-175.

[7] H. Yan, "Management Evaluation of Green Marketing Performance from the Grey System Theory Perspective [J]", Commercial Times, vol. 36, (2013), pp. 64-65.

[8] J. Lin and Y. Cheng, "Grey Multi-level Evaluation Model of Enterprise Marketing Resources [J]", Statistics and Decision, vol. 7, (2009), pp. 60-62.

[9] Z. Song and L. Zhao, "Construction and Analysis of Marketing Capability Evaluation Model [J]", Commercial Times, vol. 24, (2011), pp. 31-32.

[10] P. Wang, D. Zhang and B. Chen, "Evaluation of multi-process plans based on fuzzy comprehensive evaluation and grey relational analysis [J]", Journal of Aerospace Power, vol. 27, no. 9, (2012), pp. 20752085.

[11] T.-c. Wang, A.-j. Yang and S.-s. Zhong, "MULTI-ATTRIBUTE EXTENSION FUZZY OPTIMIZED DECISION-MAKING MODEL OF SCHEME DESIGN [J]”, Tehnički vjesnik/Technical Gazette, vol. 21, no. 2, (2014), pp. 239-247.

[12] Y. Ma, L. Wang and W. Yuan, et al. "Study on selection of water turbine type based on fuzzy-AHP and its application [J]", Journal of Hydroelectric Engineering, vol. 32, no. 2, (2013), pp. 261-264+276. 
[13] M. Li, "Study on Enterprise Human Resource Competitiveness Evaluation Based on Interval Number Fuzzy Comprehension Evaluation (IN FCE) [J]”, Enterprise Economy, vol. 3, (2013), pp. 92 - 95.

[14] L. Lv, Y. Liang and C. Peng, "Enterprises Green Degree of Green Supply Chain Management based on Fuzzy-AHP Model [J]”, Science Technology and Industry, vol. 3, (2008), pp. 1-5.

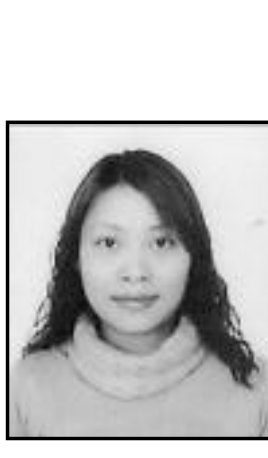

\section{Author}

Fei Lu, in 2005, she was graduated from Southwest University majoring in master of Finance, and then she has been working in Chongqing academy of social and science from 2006. She had published 6 papers in the following journals, such as Commercial Times, Chongqing Finance, New Chongqing, Managerialist, Assets and Finances, Journal of Chongqing. Now, she is an assistant researcher and her scientific interests are Economic Management and Finance. 
International Journal of $u-$ and e-Service, Science and Technology Vol. 7, No. 6 (2014) 